\title{
An Arson Investigation by using Comprehensive Two-dimensional Gas Chromatography-Quadrupole Mass Spectrometry
}

\author{
Taylor $\mathrm{CM}^{1}$, Rosenhan $\mathrm{AK}^{2}$, Raines $\mathrm{JM}^{3}$ and Rodriguez $\mathrm{JM}^{3,4 *}$
}

'SHIMADZU, 7102 River wood Dr., MD 21046, USA

${ }^{2}$ Oktibbeha County Fire Services, Drawer KJ, Mississippi State, MS 39762, USA

${ }^{3}$ Mississippi State Chemical Laboratory, PO Box CR, Mississippi State, MS 39762, USA

${ }^{4}$ Department of Biochemistry and Molecular Biology, Mississippi State University Mississippi State, MS 39762, USA

\begin{abstract}
The aim of this investigation is to develop a new tool for the investigation of hydrocarbon accelerants. The chemical analysis of fire debris in an arson investigation has gone through several developmental stages. The nature of the analysis has been divided into three essential components due to the complexity of the samples. The first has been the extraction of the accelerants from the debris. The second has been the development of instrumental techniques for the analysis of extracted samples. The interpretation of the results is the final stage. In our investigation, we have used comprehensive two-dimensional gas chromatography-quadrupole mass spectrometry (GCXGC-qMS). GCXGC-qMS is well suited for the analysis of complex hydrocarbon accelerants. We applied the resolution and separation powers of the GCXGC with the high precision mass scanning capabilities of a quadrupole mass spectrometer to investigate these complex samples. Total and selective ion scans were performed on samples obtained from an arson investigation. By using this process, we were able to conclusively determine the presence of hydrocarbon accelerants in fire debris.
\end{abstract}

Keywords: Comprehensive two-dimensional gas chromatographyquadrupole mass spectrometry; Arson; Accelerants; Gasoline; Kerosene; Diesel

\section{Introduction}

During 2010, law enforcement agencies reported 56,825 arsons to the Federal Bureau of Investigation, at an estimated total direct cost of over $\$ 1.5$ billion in property damage. One out of every four fires is due to arson [1]. The National Fire Protection Association estimates approximately 300 to 350 civilian deaths per year due to arson. The injury rate per fire is 5.6 firefighter injuries per 100 structure fires due to arson [2]. Arson is a felony that costs heavily in human and monetary terms.

An arson investigation usually starts by looking at the four factors that must be present in order to create and sustain a fire. These four factors are known as the fire tetrahedron [3]. The tetrahedron consists of a chemical reaction, flammable substance, starting heat source and oxygen. The starting heat source needs to match the ignition temperature of the flammable substance. In order to classify a fire as arson, the investigator has to prove tampering with at least one of the factors in the fire tetrahedron.

A common arsonist's practice is the use of flammable materials and accelerants; where accelerants are ignitable fluids. Widespread accelerants used in this trade are usually hydrocarbon liquids i.e., kerosene, diesel or gasoline.

Debris from suspected arson fires are routinely analyzed for trace amounts of hydrocarbon accelerants. The samples of debris are usually sealed at the fire scene, in an airtight container, i.e., a new unlined metal paint can. Procedures for labeling the samples are given in ASTM E1459 [4].The samples are brought to the lab for analysis. The procedures for receiving, documenting, storing and retrieving are given in ASTM E1492-11[5]. The analysis is accomplished in three stages. The first stage consists of concentration and extraction of the suspected accelerants from the debris. The second stage involves the instrumental analysis of the concentrated extracted samples. Finally, the last stage involves the interpretation and analysis of results [6].

Much of research has gone into the first stage. Steam distillation [7] and solvent extraction [8] were historically the first methods used in the extraction and concentration of the suspected accelerants from the debris [9]. Distillation of debris samples using steam or high boiling point solvents, i.e., ethylene glycol, produces a floating layer on top of the distillate that can be used in the second stage of the investigation [10]. Distillation is a labor intensive process which can take forty eight hours or more to complete. Furthermore, the distillation rate may influence the extraction [11]. Due to the complexity of this method, the ASTM International subcommittee E30.01 withdrew this standard, ASTM E1385-00, as a procedure. On the other hand, solvent extraction is fast; however, undesirable components may be extracted from the matrixes that interfere with the analysis.

Forensic investigators have searched for better methods for the separation and concentration of the accelerants from fire debris. It involved sampling by direct [12], dynamic [13] or passive headspace with activated charcoal or solid phase microextraction $[14,15]$.

Direct headspace sampling extracts the volatile components in the gas portion above the sample. This method turned out to be less

*Corresponding author: Mississippi State Chemical Laboratory, PO Box CR Mississippi State MS 39762, USA, Tel: 362-325 2653; Fax: 362-325 7807; E-mail: jrm385@msstate.edu

Received September 22, 2012; Accepted October 20, 2012; Published October 22, 2012

Citation: Taylor CM, Rosenhan AK, Raines JM, Rodriguez JM (2012) An Arson Investigation by using Comprehensive Two-dimensional Gas ChromatographyQuadrupole Mass Spectrometry. J Forensic Res 3:169. doi:10.4172/21577145.1000169

Copyright: (c) 2012 Taylor CM, et al. This is an open-access article distributed under the terms of the Creative Commons Attribution License, which permits unrestricted use, distribution, and reproduction in any medium, provided the original author and source are credited. 
Citation: Taylor CM, Rosenhan AK, Raines JM, Rodriguez JM (2012) An Arson Investigation by using Comprehensive Two-dimensional Gas Chromatography-Quadrupole Mass Spectrometry. J Forensic Res 3:169. doi:10.4172/2157-7145.1000169

Page 2 of 8

sensitive and it was only useful in the detection of highly volatile accelerants, i.e. alcohol and lacquer thinners.

Dynamic headspace involves a flow of an inert gas through the sample vessel. The volatile accelerants are collected into a trap. The trap can be charcoal, Porapak Q, Tenax, Amberlite XAD, etc. Desorption into the analyzing instrument can be done by using a "stripping" solvents or by heating.

Dietz introduced passive headspace with activated charcoal strips in $1985[16,17]$. Charcoal strips traps and concentrate the volatiles in the headspace above the sample. A solvent, i.e. carbon disulfide, $\mathrm{n}$-pentane, desorbs the volatiles absorbed by the strips $[18,19]$. This is a very sensitive method; which can concentrate and isolate small quantities of accelerants from fire debris.

Solid phase microextraction selectively concentrates fire debris volatiles into an absorbent fiber. This method, as the previous one, is very sensitivity; however, it has the advantage that no solvent is used $[20,21]$. ASTM International has formalized this method in ASTM E2154 [15].
Instrumentally, forensic investigators have used GC-FID [18,19,22,23], GC/MS [24-26], GC/MS/MS [27], FT-ICR [28], GCXGC $[29,30]$.

ASTM International E30 committee formally withdrew the test method for analyzing fire debris ignitable liquid residues samples by gas chromatography, ASTM E1387 and recommended the use of GC/ MS for this type of analysis, ASTM E1618.

Pert et al. [31] commented on the advantages of using GCXGC in the analysis of complex arson samples. It is the purpose of this study is to show that GCXGC-qMS can be used in this type of investigation.

\section{Experimental \\ GC X GC/MS}

The GC/MS system used was a Shimadzu QP 2010 Ultra (Shimadzu Scientific Instruments, Inc., Columbia, MD). This is a gas chromatograph-quadrupole platform. As a general rule, quadrupole mass spectrometers have a relatively slow scan speed and this has become a limiting factor for usage of quadrupoles in comprehensive

\begin{tabular}{|l|l|}
\hline Injection & $1.0 \mu \mathrm{L}$. Injector Temperature $325^{\circ} \mathrm{C}$. Pressure $70.1 \mathrm{kPa}$. Split: $10: 1$. \\
\hline First column & $30 \mathrm{~m} \times 0.25 \mathrm{~mm} \times 0.50 \mu \mathrm{m}, 50 \%$ Phenyl Polysilphenylene siloxane (BPX50, SGE Analytical Sc. Austin, TX). \\
\hline Modulator & Period $4.0 \mathrm{~s}$. Con $1330^{\circ} \mathrm{C}$ \\
\hline Second column & $2 \mathrm{~m} \times 0.1 \mathrm{~mm} \times 0.1 \mu \mathrm{m}, 100 \%$ Polydimethylsiloxane (BPX1, SGE Analytical Sc., Austin, TX). \\
\hline Oven program & $40^{\circ} \mathrm{C}$ for $2 \mathrm{~min} .40-325^{\circ} \mathrm{C} @ 5^{\circ} \mathrm{C} \mathrm{min}^{-1} \mathrm{Hold}$ at $325^{\circ} \mathrm{C}$ for $30 \mathrm{~min}$. \\
\hline
\end{tabular}

Table 1: GC Experimental Parameters.

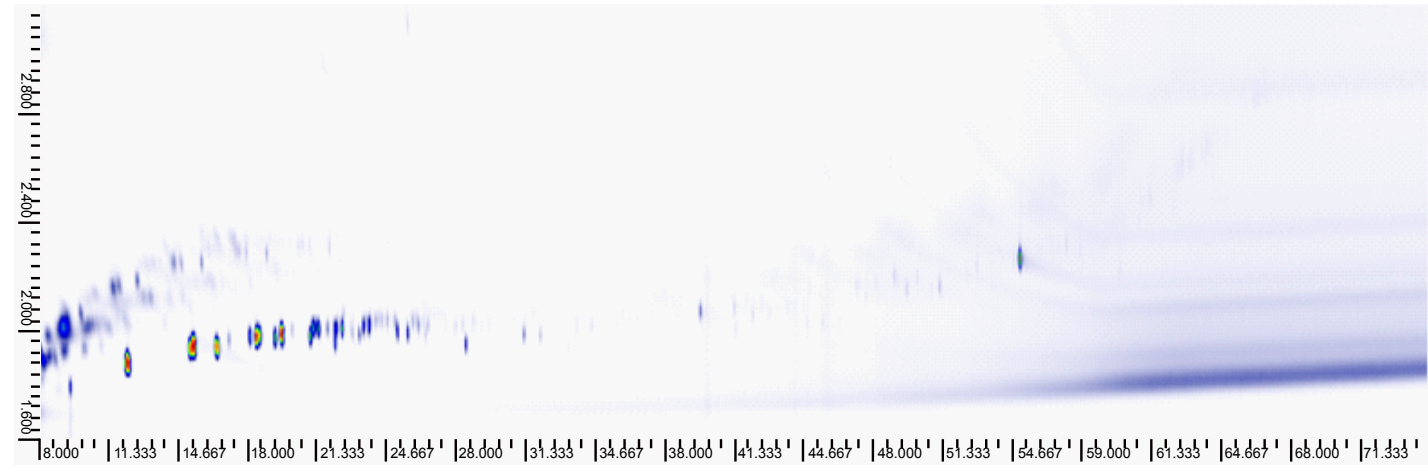

Figure 1: Comprehensive GCXGC-qMS total ion chromatogram of gasoline. X-axis: First dimension, retention time in seconds. Separation based on polarity. $Y$-axis: Second dimension, volatility-base separation in seconds.

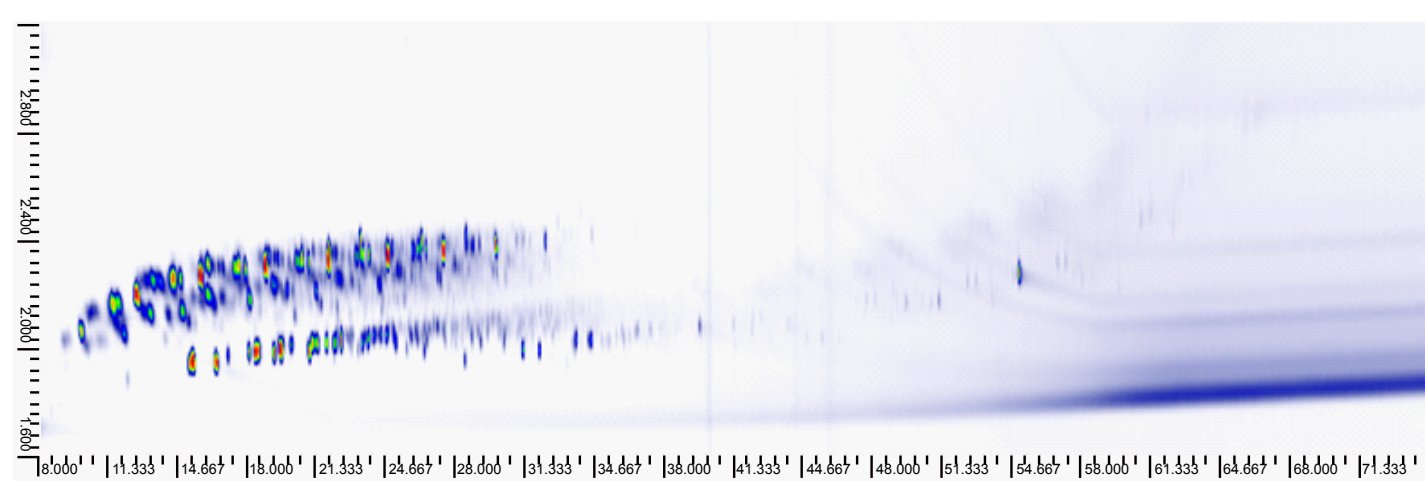

Figure 2: Comprehensive GCXGC-qMS total ion chromatogram of kerosene. X-axis: First dimension, retention time in seconds. Separation based on polarity. Y-axis: Second dimension, volatility-base separation in seconds. 
Citation: Taylor CM, Rosenhan AK, Raines JM, Rodriguez JM (2012) An Arson Investigation by using Comprehensive Two-dimensional Gas Chromatography-Quadrupole Mass Spectrometry. J Forensic Res 3:169. doi:10.4172/2157-7145.1000169

Page 3 of 8

GCXGC-MS. The maximum allowed data acquisition speeds have been $30 \mathrm{~Hz}$. This is too slow to provide enough points for the ultra sharp peaks generated by comprehensive GCXGC. However, this instrument is equipped with a firmware, Advanced Scanning Speed Protocol

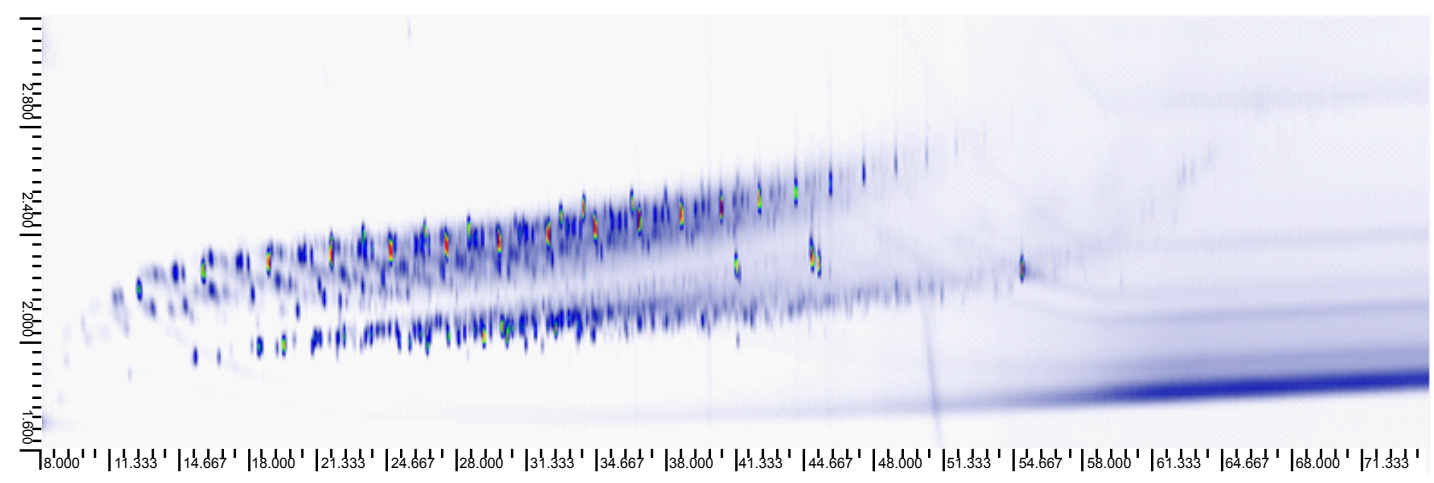

Figure 3: Comprehensive GCXGC-qMS total ion chromatogram of diesel. X-axis: First dimension, retention time in seconds. Separation based on polarity. Y-axis: Second dimension, volatility-base separation in seconds.

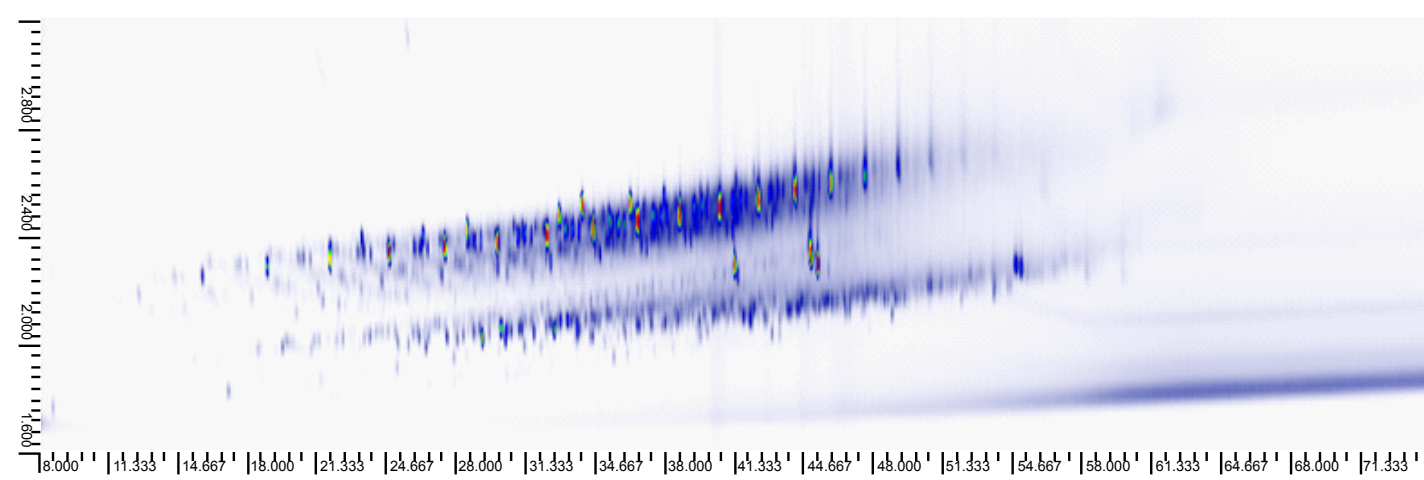

Figure 4: Comprehensive GCXGC-qMS total ion chromatogram of suspected arson sample. X-axis: First dimension, retention time in seconds. Separation based on polarity. Y-axis: Second dimension, volatility-base separation in seconds.

\section{Compounds}

Alkanes

C1 to C4 alkylbenzenes

Alicyclics and olefinics hydrocarbon

Benzene, C1 to C3 alkylbenzenes

C4 to C5 alkylbenzenes

Alkylnaphthalenes

aBoldfaced ions represent the selected ions

Table 2: Characteristic ions for accelerant pattern identification $[31,40]$. $\mathrm{m} / \mathrm{z}^{\mathrm{a}}$

\section{$57,71,85,99$}

$91,105,114$

$55,69,83,97$

$78,92,106,120$

$119,134,148,162$

$128,142,156,170$

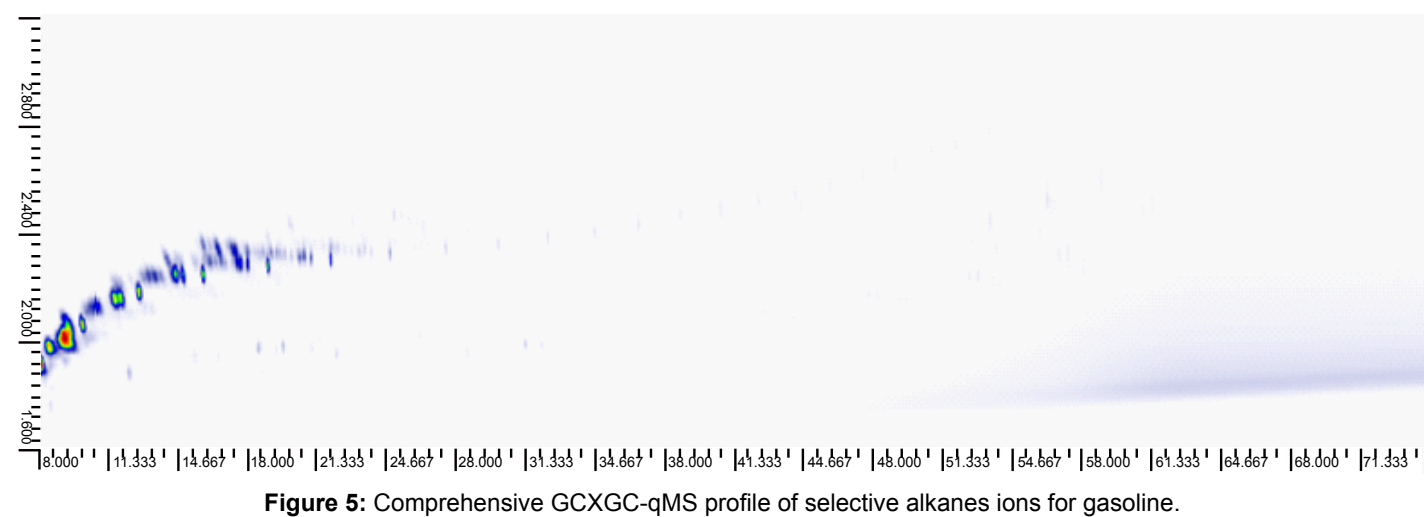


(ASSP), and a fast data collection algorithm, which allows for faster collection rates.

A two-stage thermal loop modulator (Zoex Corp. Lincoln, NE) was mounted on top of the GC oven in order to provide comprehensive twodimensional gas chromatography capabilities. This system employs two gas jets, a cold and a hot jet. The single cold jet cools two different segments of the second column, entrapping the compounds in the two sections of the second column. The hot jet, positioned perpendicular to the cold one, releases the entrapped compounds. A detailed description of the two-stage loop modulator system was provided by E. B. Ledford et al. [32]

Gas chromatograph experimental parameters and columns are listed in table 1 . The first column was selected with a high polarity phase and the second was non-polar. The separation occurred via a polar-by-volatile interaction with the samples. Therefore, the samples were separated by polarity in the $\mathrm{x}$-axis and by boiling point $\mathrm{y}$-axis retention times.

The MS data was collected with Shidmazu GC/MS Real Time Analysis. The GCXGC-q MS data was analyzed by using GC Image V 2.1 ( Zoex Corp.).

\section{Sample Preparation}

Samples of gasoline, kerosene and diesel were prepared by diluting $0.09 \mathrm{~g}$ of each sample into 10 milliliters of methylene chloride. Arson samples were extracted with methylene chloride. Purposely, we selected solvent extraction. As previously stated, this sample extraction and concentration technique is rather sensitive, but troublesome. The solvent can extract undesirable compounds from the matrix that can interfere with the analysis.

\section{Results and Discussion}

Comprehensive GCXGC works on the principles established by J. B. Phillips [33-35]. It involves the separation by two orthogonal gas chromatographic columns. The sample is separated into fractions and each fraction is transferred and cryogenic focusing to a secondary column with different polarity than the first. The second separation is faster than the first; so, the separation obtained from the first can be maintained. Thus, chemical compounds are separated by their independent chemical properties interacting with two orthogonal column phases. [36-38]. We selected as the first column a polar column. Since the most polar compounds in the sample are aromatic, polyaromatic hydrocarbons and polyaromatic heterocycles, they are regularly spaced along the base of the two-dimensional GCXGC chromatogram. They appear in order of increasing polarity. The first to elute are the mono-aromatic compounds followed by the two, three-ring, and heterocyclic aromatic compounds. The non-polar paraffinic components have the weakest interaction with the first column, and then the second non-polar column separates them. They emerge according to their volatility. They form the top band in the two-dimensional GCXGC chromatogram. Between these two bands, compounds with intermediated polarity and volatility will reside, i.e. alkylated mono-aromatic and polyaromatic compounds.

In order to identify the sample components, we coupled a GCXGC to a quadrupole mass spectrometer. Frysinger et al. [39] coupled a quadrupole mass spectrometer to a GCXGC system. They concluded that due to the high resolution and narrow peaks generated by the GCXGC system, a faster scanning mass spectrometer was required. Our quadrupole mass spectrometer, equipped with ASSP can scan at a faster rate than previous quadrupoles mass spectrometers and therefore, it can handle the high resolution and narrow peaks generated by GCXGC.

Mass spectra data was collected throughout the whole chromatographic runs of gasoline, kerosene, diesel and a suspected arson sample. The software identifies peaks as "blobs". A blob is a collection of the pixels that make up each peak. Each blob contains information, which identifies the two dimensional retention time and the mass spectra of the compound that makes up the collection of pixels. Furthermore, the sum of the pixels value of each blob is proportional to the quantity of the compound that composes that blob. The software allows selection of minimum area, volume and peak area for blob selection. Blob selection can also be performed by computer cursor selection of a specific blob. Total ion chromatograms for the samples (gasoline, kerosene, diesel and suspected arson sample) are shown in figures 1-4.

Total ion chromatograms can generate chromatographic patterns, which can be useful and at the same time deceiving. Pyrolysis of nonaccelerant matrices may generate chromatographic patterns that may interfere in recognizing the accelerant distinctive fingerprint patterns. Individual compound identification is insignificant in an arson investigation. The overall fingerprint pattern recognition of the accelerant is the method of confirming their presence.

Fingerprint pattern of selective diagnostic ions that are associated with hydrocarbon accelerants can be used for the screening and identification of a particular accelerant. The diagnostic ions that are used for these types of identifications are given in table 2 .

The sets for alkanes $(57,71,85,99) \mathrm{m} / \mathrm{z}^{\mathrm{a}}$, alkylbenzenes $(91,105,119$,

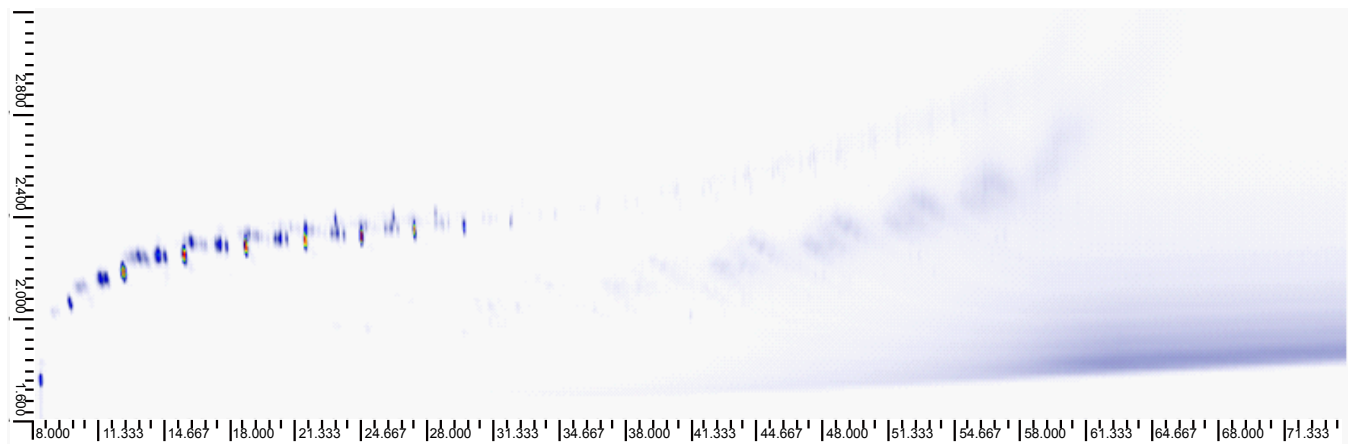

Figure 6: Comprehensive GCXGC-qMS profile of selective alkanes ions for kerosene. 
Citation: Taylor CM, Rosenhan AK, Raines JM, Rodriguez JM (2012) An Arson Investigation by using Comprehensive Two-dimensional Gas Chromatography-Quadrupole Mass Spectrometry. J Forensic Res 3:169. doi:10.4172/2157-7145.1000169

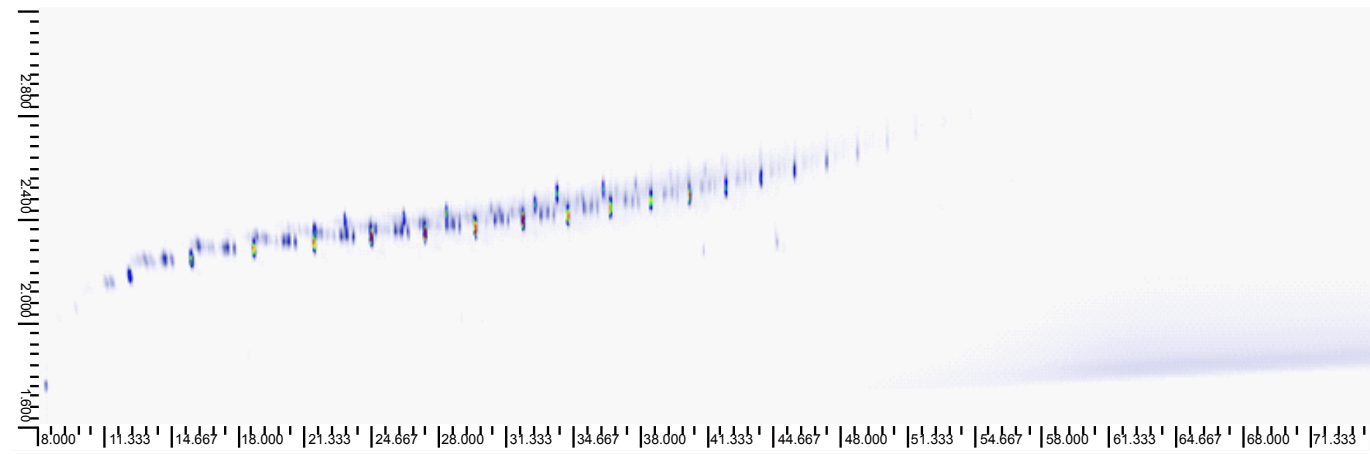

Figure 7: Comprehensive GCXGC-qMs profile of selective alkanes ions for diesel.

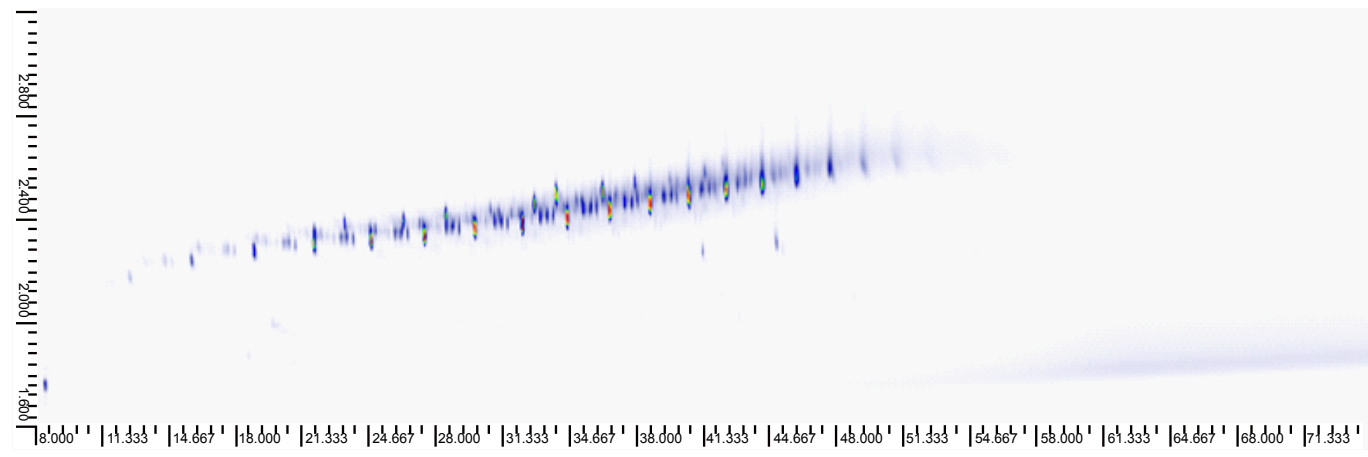

Figure 8: Comprehensive GCXGC-qMS profile of selective alkanes ions for the suspected arson sample.

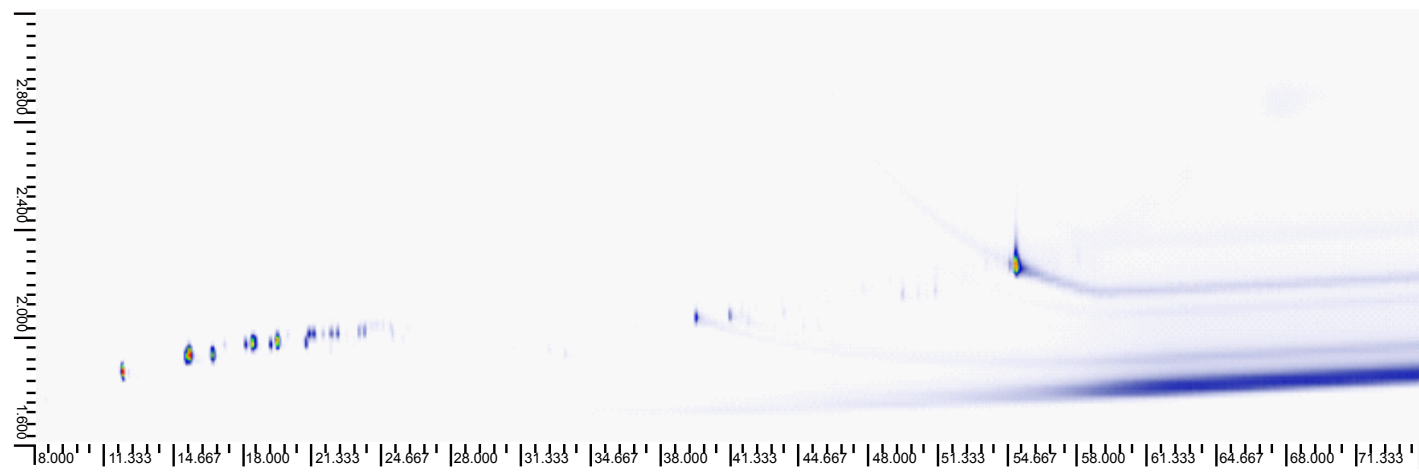

Figure 9: Comprehensive GCXGC-qMS profile of selective alkylbenzenes ions for gasoline.

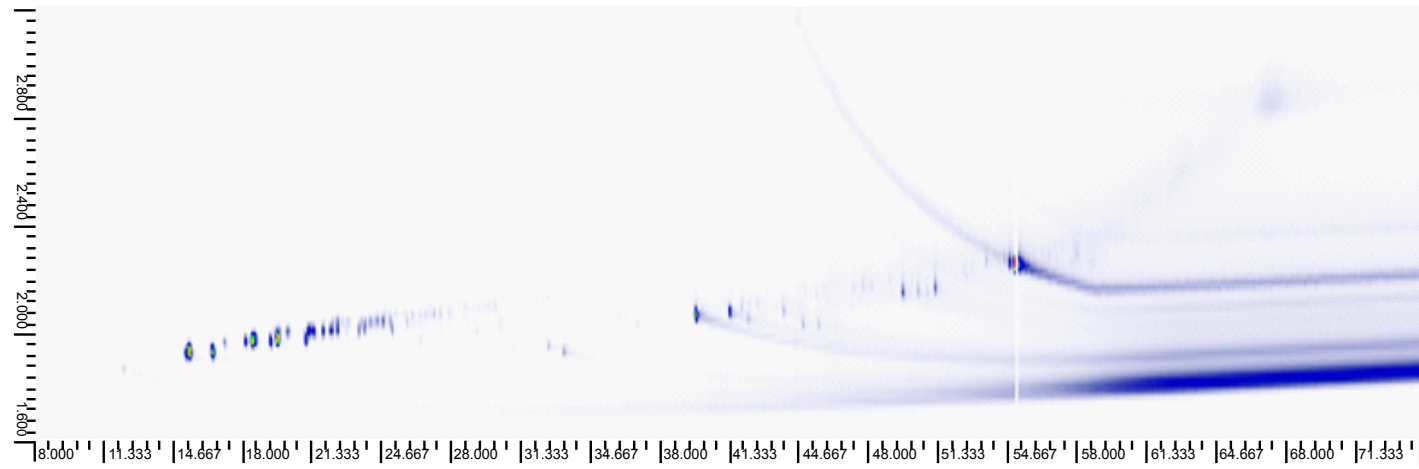

Figure 10: Comprehensive GCXGC-qMS profile of selective alkylbenzenes ions for kerosene. 
Citation: Taylor CM, Rosenhan AK, Raines JM, Rodriguez JM (2012) An Arson Investigation by using Comprehensive Two-dimensional Gas Chromatography-Quadrupole Mass Spectrometry. J Forensic Res 3:169. doi:10.4172/2157-7145.1000169

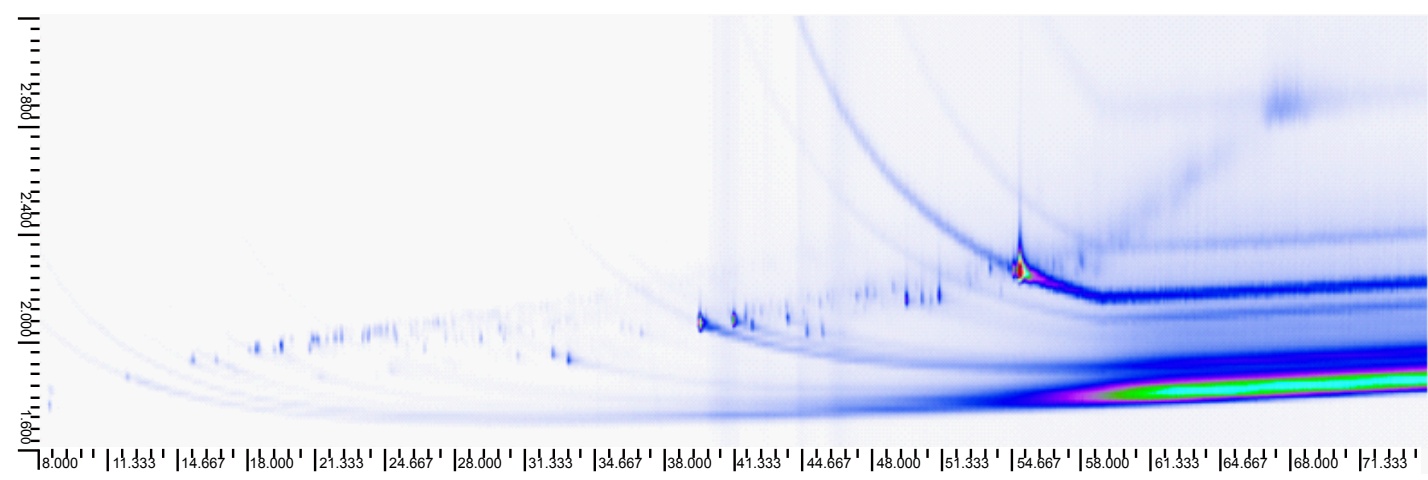

Figure 11: Comprehensive GCXGC-qMS profile of selective alkylbenzenes ions for diesel.

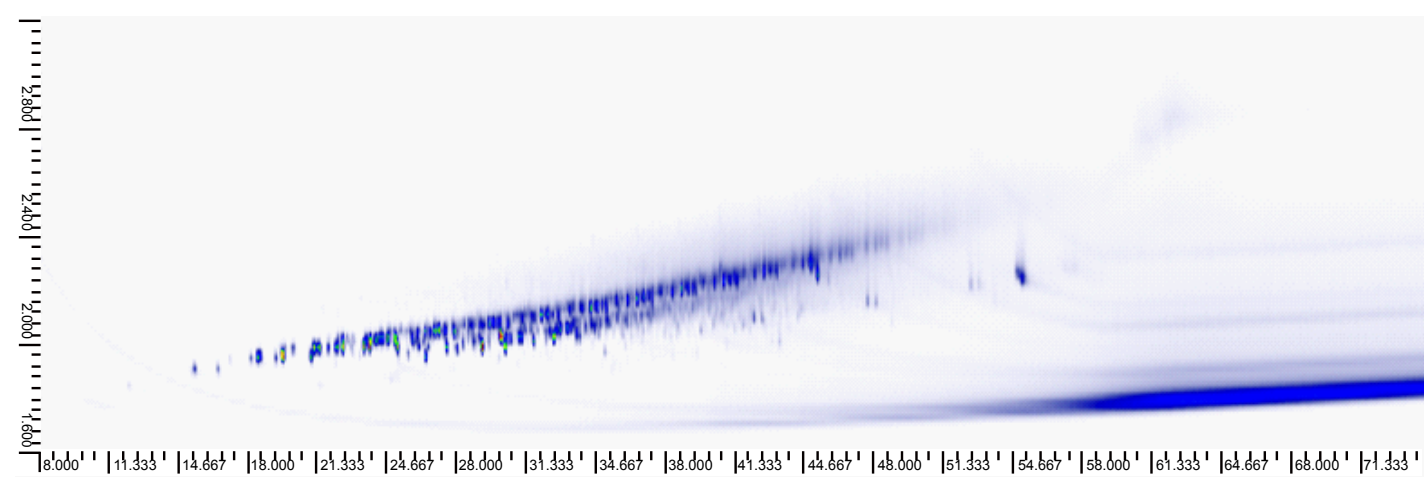

Figure 12: Comprehensive GCXGC-qMS profile of selective alkylbenzenes ions for the suspected arson sample.

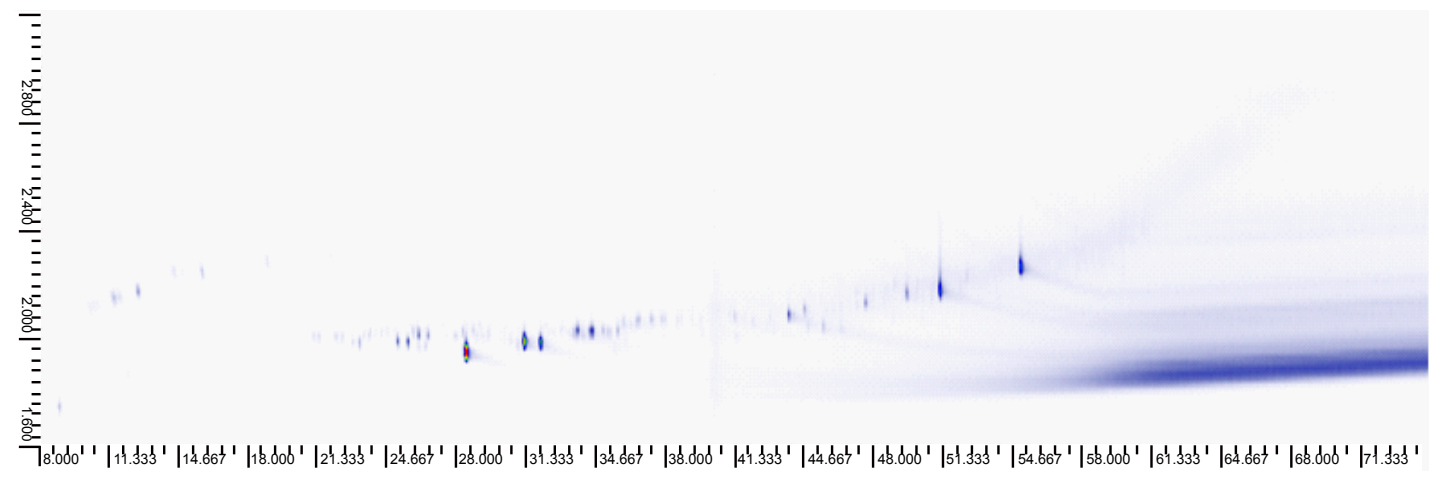

Figure 13: Comprehensive GCXGC-qMS profile of selective alkylnaphthalenes ions for gasoline.

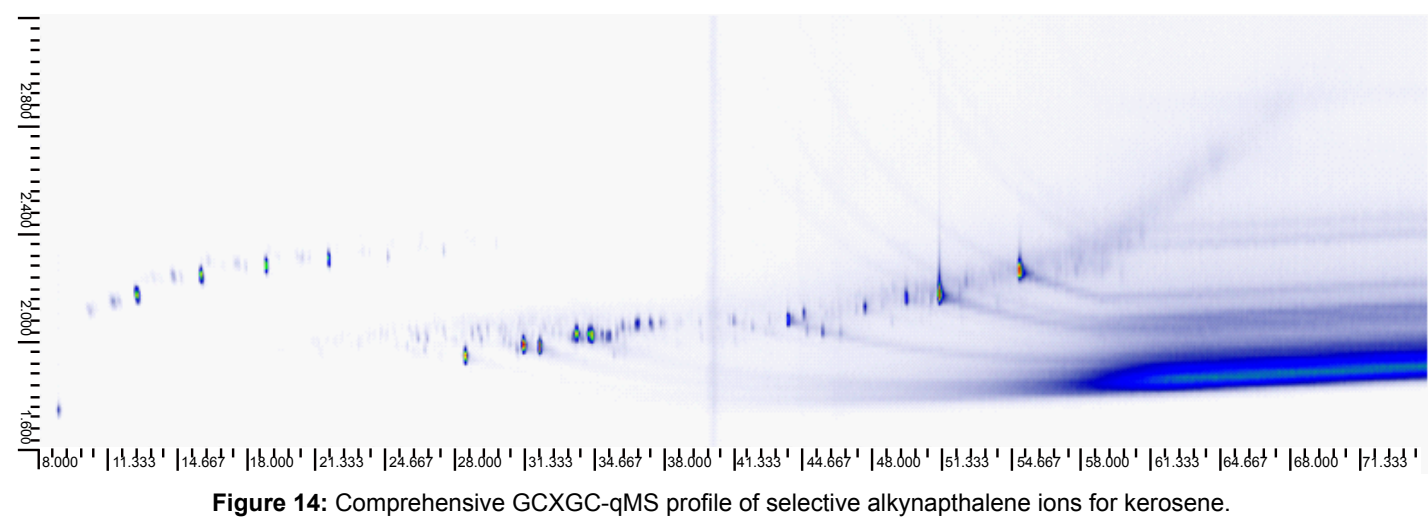


Citation: Taylor CM, Rosenhan AK, Raines JM, Rodriguez JM (2012) An Arson Investigation by using Comprehensive Two-dimensional Gas Chromatography-Quadrupole Mass Spectrometry. J Forensic Res 3:169. doi:10.4172/2157-7145.1000169

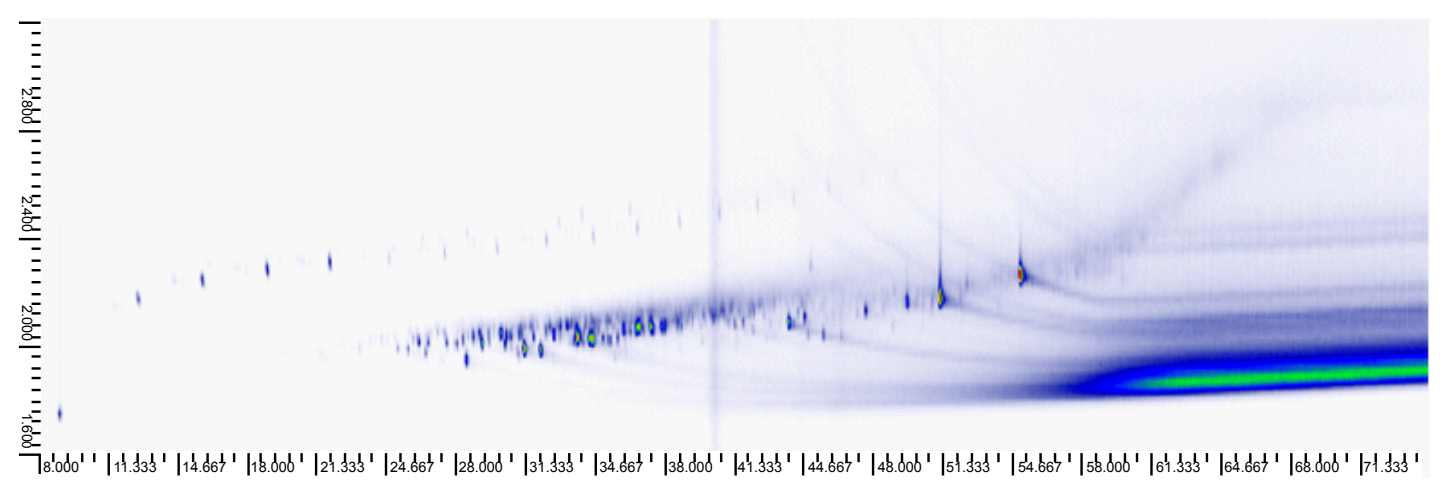

Figure 15: Comprehensive GCXGC-qMS profile of selective alkylnapththalenes ions for diesel.

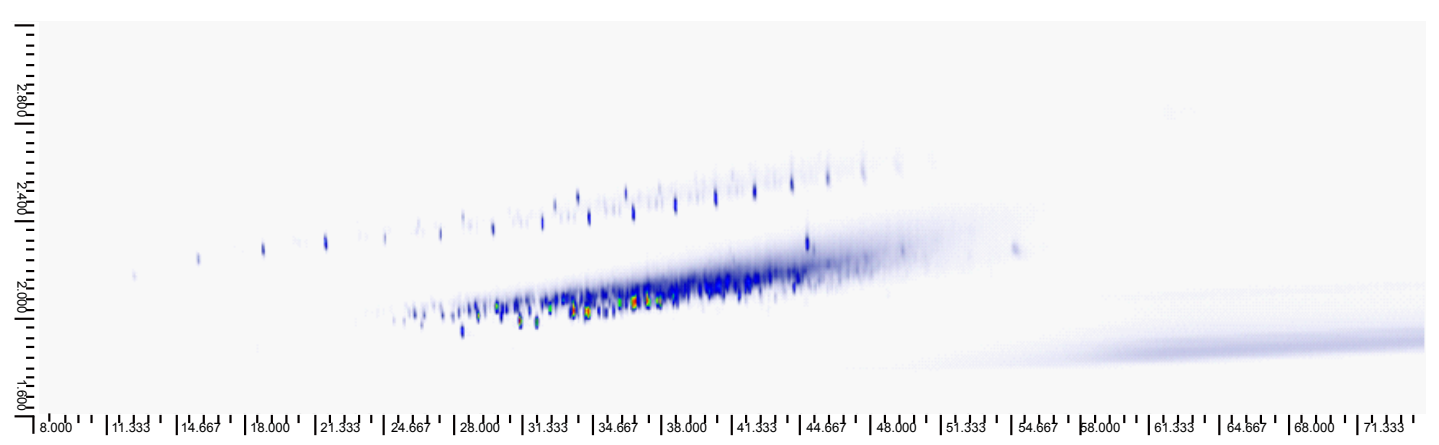

Figure 16: Comprehensive GCXGC-qMS profile of elective alkylnapthalene ions for suspected arson sample.

134) $\mathrm{m} / \mathrm{z}^{\mathrm{a}}$ and alkylnaphthalenes $(128,142,156,170) \mathrm{m} / \mathrm{z}^{\mathrm{a}}$ were used in this investigation. The selective ion chromatograms for these ions sets for gasoline, kerosene, diesel and the suspected arson sample are given in figures 5-16. From the selective ion chromatograms, it was possible to visualize the fingerprint pattern of an accelerant in the suspected arson sample. A fairly close match was observed between the diesel and the suspected arson sample. The light portions of the chromatographs are slightly different. The low boiling components of the accelerants are usually the first to be consumed by the fire. Therefore, it was possible to positively confirm the presence of accelerant (possibly diesel) in the suspected arson sample.

\section{Conclusions}

Hydrocarbon accelerants and a suspected arson sample were analyzed by comprehensive two-dimensional gas chromatographyquadrupole mass spectrometry (GCXGC-qMS). GCXGC-qMS has the advantage of using two orthogonal gas chromatographic columns. The first being a polar column and the second being a non-polar column, the detector was a fast scanning quadrupole mass spectrometer. By using SIM, a two dimensional separation of the samples was achieved. Clearly by using SIM of selective target ions, we can generate fingerprint patterns that can be useful in identifying accelerants in fire debris samples.

\section{Acknowledgements}

Alex Mutin of Shimadzu Scientific Instrument provided the GC/MS for conducting the experiment and Edward Ledford of Zoex Corporation provided the modulator and software. Mississippi State Chemical Laboratory provided samples of accelerants. Oktibbeha County Fire Services provided the fire debris samples.

\section{References}

1. http://www.fbi.gov/about-us/cjis/ucr/crime-in-the-us/2010

2. http://www.nfpa.org

3. http://en.wikipedia.org/wiki/Firefire_tetrahedron.svg

4. American Society for Testing and Materials, ASTM E1459-92 (2005) Standard Guide for Physical Evidence Labeling and Related Documentation.

5. American Society for Testing and Materials, ASTM E1492-11 Standard Practice for Receiving, Documenting, Storing, and Retrieving Evidence in a Forensic Science Laboratory.

6. Stauffer E, Lentini J (2003) ASTM standards for fire debris analysis: a review Forensic Sci Int 32: 63-67.

7. American Society for Testing and Materials, ASTM E1385-00 (2001) Standard Practice for Separation and Concentration of Ignitable Liquid Residues from Fire Debris Samples by Steam Distillation. Annual Book of ASTM Standards.

8. American Society for Testing and Materials, ASTM E1386-10. Standard Practice for Separation and Concentration of Ignitable Liquid Residues from Fire Debris by Solvent Extraction.

9. Camp MJ (1980) Analytical Techniques in Arson Investigation. Anal Chem 52 422A-426A.

10. Clodfelter RW, Hueske EE (1997) A Comparison of Decomposition Products from Selected Burned Materials with Common Arson Accelerants. J Forensic Sci 22: 116-118.

11. Armstrong AT, Witlkower RS (1978) Identification of Accelerants in Fire Residues by Capillary Column Gas Chromatography. J Forensic Sci 23: 662671.

12. American Society for Testing and Materials, ASTM E1388-05 Standard Practice for Sampling of Headspace Vapors from Fire Debris Samples.

13. American Society for Testing and Materials, ASTM E1413-07, Standard Practice for Separation and Concentration of Dynamic Headspace Concentration. 
Citation: Taylor CM, Rosenhan AK, Raines JM, Rodriguez JM (2012) An Arson Investigation by using Comprehensive Two-dimensional Gas Chromatography-Quadrupole Mass Spectrometry. J Forensic Res 3:169. doi:10.4172/2157-7145.1000169

14. American Society for Testing and Materials, ASTM E1412-07. Standard Practice for Separation of Ignitable Liquid Residues from Fire Debris Sample by Passive Headspace Concentration with Activated Charcoal.

15. American Society for Testing and Materials, ASTM E2154-01(2008). Standard Practice for Separation and Concentration of Ignitable Liquid Residues from Fire Debris Samples by Passive Headspace Concentration with Solid Phase Microextraction (SPME).

16. Dietz WR (1985) Evaluation of simple diffusion techniques for accelerant recovery. Combined Meeting of Forensic Science Societies.

17. Dietz WR (1991) Improved charcoal packaging for accelerant recovery by passive diffusion. J Forensic Sci 36: 111-121.

18. Newman TR, Dietz WR, Lothridge K (1996) The use of Activated Charcoal Strips for Fire Debris Extractions by Passive Diffusion; Part 1: The Effects of Time, Temperature, Strip Size, and Sample Concentration. J Forensic Sci 41: $361-370$.

19. Palmer LA, Waters LV (1993) Multiple Analysis of Fire Debris Samples Using Passive Headspace Concentration. J Forensic Sci 38: 165-183.

20. Ahmad UK, Selvaraju G (2007) Forensic Detection of Fire Accelerants Using A New Solid Phase Microextraction (SPME) Fiber. Internet J Forensic Sci 2: 1-16.

21. Sandercock PM, Du Pasquier E (2003) Chemical fingerprinting of unevaporated automotive gasoline samples. Forensic Sci Int 134: 1-10.

22. Andrasko J (1983) The Collection and Detection of Accelerant Vapors Using Porous Polymers and Curie Point Pyrolysis Wire Coated with Active Carbon. J Forensic Sci 28: 330-334

23. American Society for Testing and Materials. ASTM E1387. Test Method for Ignitable Liquid Residues in Extracts from Fire Debris Samples by Gas Chromatography.

24. Frontel L, Pozas JA, Picabea L (1995) A comparison of extraction and adsorption methods for the recovery of accelerants from arson debris. Forensic Sc Int 75: 11-23.

25. Mach MH (1997) Gas Chromatography-Mass Spectrometry of Simulated Arson Residue Using Gasoline as an Accelerant. J Forensic Sci Soc 22: 348-357.

26. American Society for Testing and Materials. ASTM E1618-11. Ignitable Liquid Residues in Extracts from Fire Debris Samples by Gas Chromatography-Mass Spectrometry.
27. de Vos B-J, Froneman M, Rohwer E, Sutherland DA (2002) Detection of Petro (Gasoline) in Fire Debris by Gas Chromatography/Mass Spectrometry/ Mass Spectrometry (GC/MS/MS). J Forensic Sci 47: 736-756.

28. Rodgers RP, Blumer EN, Freitas MA, Marshall AG (2001) Compositiona analysis for identification of arson accelerants by electron ionization Fourier transform ion cyclotron resonance high-resolution mass spectrometry. J Forensic Sci 46: 268-279.

29. Frysinger GS, Gaines RB, Reddy CM (2002) GCXGC-A New Analytical Tool for Environmental Forensics. Environ Forensics 3: 27-34.

30. Frysinger GS, Gaines RB (2002) Forensic analysis of ignitable liquids in fire debris by comprehensive two-dimensional gas chromatography. J Forensic Sci 47: 471-482.

31. Pert AD, Baron MG, Birkett JW (2005) Review of Analytical Techniques for Arson Residue. J Forensic Sci 51: 1033-1049.

32. http://www.zoex.com/docs/technotes/technote_kt030606-1.html

33. Phillips JB, Liu Z (1992) Chromatographic Technique and Apparatus. U.S Patent No. $5,135,549$.

34. Phillips JB, Liu Z (1993) Apparatus and Method for Multi-dimensional Chemical Separation. U.S. Patent No. 5,196,039.

35. Phillips JB, Xu J (1995) Comprehensive multi-dimensional gas chromatography J Chromatogr A 703: 327-334.

36. Ventrakanami CJ, Xu J, Phillips JB (1996) Separation Orthogonally in Temperature-Programmed Comprehensive Two-Dimensional Gas Chromatography. Anal Chem 68: 1486-1492.

37. Bertsch W (1999) Two Dimensional Gas Chromatography Concepts Instrumentation and Applications-Part 1: Fundamentals, Conventional TwoDimensional Gas Chromatography, Selected Applications. J High Resolut Chromatogr 22: 647-665.

38. Bertsch W (2000) Two Dimensional Gas Chromatography Concepts Instrumentation and Applications-Part 2: Comprehensive Two-Dimensional Gas Chromatography. J High Resolut Chromatogr 23: 167-181.

39. Frysinger GS, Gaines RB (1999) Comprehensive Two-Dimensional Gas Chromatography with Mass Spectrometric Detection (GCXGC/MS) Applied to the Analysis of Petroleum. J High Resolut Chromatogr 22: 251-55.

40. http://www.leco.com/resources/application_notes. 